- Review Article

\title{
Cancer Survivorship in Primary Care
}

\author{
Jihun Kang ${ }^{1,+}$, Eun Ju Park ${ }^{2,+}$, Jungkwon Lee ${ }^{3, *}$ \\ 'Department of Family Medicine, Kosin University Gospel Hospital, Kosin University College of Medicine, Busan, Korea \\ ${ }^{2}$ Department of Family Medicine, Pusan National University Yangsan Hospital, Yangsan, Korea \\ ${ }^{3}$ Department of Family Medicine, Samsung Medical Center, Sungkyunkwan University School of Medicine, Seoul, Korea
}

With the early detection of cancer and improvement in cancer therapy, the number of cancer survivors is rapidly increasing. This number is expected to reach 2 million by the end of 2019. Cancer survivors struggle with not only cancer-related health problems but also diverse acute and chronic diseases. These health issues make cancer survivorship more complex, and proper care coordination is necessary. This study aimed to summarize the definition of cancer experience and management of cancer survivors, specifically focused on gastric, colorectal, lung, breast, thyroid, prostate, and cervical cancers. Furthermore, it aimed to discuss the role of primary care in cancer survivorship and survivorship care models and the National Policy for Cancer Survivors and Future Challenges.

Keywords: Cancer Survivors; Survivorship; Primary Health Care; Health Promotion

\footnotetext{
Received: September 11, 2019, Revised: October 25, 2019, Accepted: October 30, 2019

${ }^{*}$ Corresponding Author: Jungkwon Lee https://orcid.org/0000-0001-5503-9605

Tel: +82-2-3410-2441, Fax: +82-2-3410-0088, E-mail: jklee@skku.edu

'These two authors contributed equally to this work.
} 


\section{INTRODUCTION}

It has become more common nowadays to find cancer survivors in primary care settings. This is because the number of cancer survivors is rapidly increasing due to an increase in the rate of early cancer detection and improvement in cancer treatment. In 2016, >1.7 million Korean individuals were living with cancer, which accounts for $3.4 \%$ of the total population. ${ }^{1)}$ Furthermore, in older individuals, cancer survivors accounted for $11.0 \%$ of the total population aged $\geq 65$ years, implying that not only cancer-related health problems but also age-related chronic diseases need to be addressed in this population. Diverse healthcare needs, including primary cancer surveillance, management of acute and chronic problems, and disease prevention services, make cancer survivorship more complex. Proper care coordination is an essential part of survivorship care. Thus, cancer survivorship has deeply entered the primary care area and become unavoidable for primary care physicians. Therefore, we aimed to review the definition of cancer experience, management of cancer survivors, role of primary care in the management of cancer survivors, survivorship care models, and the National Policy for Cancer Survivor and Future Challenges.

\section{DEFINITION OF CANCER SURVIVORS AND SURVIVORSHIP}

A cancer survivor refers to an individual who is diagnosed with cancer, regardless of the course of the disease. Cancer survivorship includes not only cancer survivors themselves but also their family members and caregivers. Although the health and psychosocial problems that cancer survivors experience as they go through their survivorship trajectory are different from those of individuals without cancer, survivors have somewhat similar experience to a certain extent along their journey. Mullan ${ }^{2)}$ described that this unique features of survivorship were similar to the seasons of the year and identified the following three seasons of survivorship: (1) acute survivorship, (2) extended survivorship, and (3) permanent survivorship. The acute survivorship phase is dominated by cancer treatments; optimal care for treatment-related adverse effects, such as pain, fatigue, and emotional distress, is important in this stage. ${ }^{3,4)}$ The extended survivorship phase is referred to as the transitioning period. This period begins after the primary treatment for cancer ends, and support care for patients having physical, psychological, and social readjustments is the mainstream of survivorship. In the permanent survivorship phase, although patients can sense that the likelihood of cancer recurrence is sufficiently low, survivors often experience difficulties in obtaining employment and health insurance. In this phase, survivors are at risk of developing secondary primary cancer and experience the late effects of cancer treatment.

In Korea, a wide range of terms such as cancer survivors, cancer overcomer, and cured cancer patients have been used to indicate cancer survivor, but no consensus has been reached with respect to the terminology. Although the term "cancer survivors" had been widely used in the previous years, an alternative term (cancer experiencer) has recently gained popularity as it does not have a negative connotation.

\section{EPIDEMIOLOGY AND ECONOMIC BURDEN OF CANCER SURVIVORS}

As the number of cancer survivors reached a million in 2014, the number of cancer survivors has continuously increased due to the early detection of cancer, improvement in cancer treatment outcomes, and preventive health behaviors among cancer survivors. ${ }^{5)}$ Based on the cancer statistics published by the Korea Central Cancer Registry in 2016, >1.7 million individuals were living with cancer, which accounts for $3.4 \%$ of the entire Korean population. ${ }^{1)}$ In 2016, 230,000 individuals were newly diagnosed with cancer. Of these, 78,000 died, and 152,000 survived. Consequently, the number of cancer survivors is predicted to exceed 2 million in Korea by the end of 2019 with this incremental trend in cancer prevalence.

The economic burden caused by cancer survivors has gradually increased, with an annual increasing rate of $8.9 \%$ from 2000 to $2010{ }^{6}$ ) While approximately 11 billion US dollars was incurred for cancer diagnosis and treatment in 2000, the amount increased to 20 billion US dollars in 2010. Based on the Korean National Health Insurance claims data, the medical expenses for cancer survivors rapidly increased in the year of cancer diagnosis and then was 2-3 times higher in the following years. ${ }^{7)}$ Cancer-related financial burden is more prevalent in patients with comorbidities. The economic burden associated with morbidity was estimated as 2.7 billion US dollars, ${ }^{8)}$ and the proportion of morbidity-related cost incurred in Korea (23\%) was much higher than that in the United States (8\%). This finding suggests the lack of comprehensive rehabilitation programs that can help cancer survivors to return to work and decrease social burden associated with cancer management.

\section{MANAGEMENT OF CANCER SURVIVORS}

Cancer survivors encounter a number of physical and psychosocial issues during the cancer survivorship journey. Although most patients with cancer and oncologists focus on the surveillance of primary cancer, optimal screening strategies for secondary primary cancer are also important. Although the screening rate for secondary primary cancer among cancer survivors was higher than that among the general population (gastric cancer, $37.1 \%$ versus $31.3 \%$; breast cancer, $50 \%$ versus $30.9 \%$; cervical cancer, $43.1 \%$ versus $36.4 \%$; colorectal cancer, $28.0 \%$ versus $21.4 \%$ ), the screening rates in Korea remained suboptimal. ${ }^{9)}$ This finding implies that more holistic approaches should be employed to deliver appropriate cancer screening for survivors.

Once cancer is diagnosed, patients' and healthcare providers' attention is shifted away from non-cancer-related medical problems. However, comorbidity, the coexistence of multiple diseases in an individu$\mathrm{al}$, is another issue encountered by this population because it increases the mortality rate among cancer survivors. ${ }^{10)}$ Because comorbidity can 
occur as a result of cancer treatment or as a late side effect of cancer treatment, such as surgery, radiation therapy, chemotherapy, and hormonal therapy, cancer survivors show higher comorbidity rates than the general population. ${ }^{11)}$ Despite the higher comorbidity rate among cancer survivors, the comprehensive management of comorbidities, including regular follow-up for diabetes, necessary heart failure care, and preventive services, has not been conducted, ${ }^{12)}$ which puts this vulnerable population at risk of premature mortality from chronic comorbid conditions. Cancer survivors who received care from both oncologists and primary care physicians were more likely to receive appropriate care for the comorbid conditions, ${ }^{12)}$ suggesting that diseasespecific, narrow subspecialty for cancer management may limit comprehensive care.

Smoking cessation occupy a large part of survivorship because smoking decreases the effectiveness of cancer treatments, increases the risk of treatment-related complications, and decreases survival time due to cancer progression and recurrence. ${ }^{13)}$ After 2 years of cancer diagnosis, the smoking rate of male cancer survivors dropped from $34.6 \%$ to $15.9 \%$; however, a slight increase in the smoking rate was reported 5 years after cancer diagnosis (16.3\%). ${ }^{14)}$ Furthermore, although the current smoking rate of male cancer survivors was lower than that of individuals without cancer (7.8\% versus $26.4 \%$ ), a significant proportion of cancer survivors (53.4\%) continued to smoke even after the diagnosis of cancer. ${ }^{15)}$ With regard to alcohol cessation, the rate of male survivors who consumed high amounts of alcohol decreased from $11.4 \%$ to $5.6 \% 2$ years after cancer diagnosis and then slightly increased to $6.6 \% 5$ years after the diagnosis. ${ }^{14)}$ Therefore, effective smoking and alcohol cessation programs incorporated into routine cancer treatment processes are necessary to address the issue of tobacco exposure and alcohol consumption especially among male cancer survivors.

Regular physical activity has been demonstrated to improve physical functioning, enhance emotional wellness, reduce fatigue, and positively affect survival outcomes. ${ }^{16)}$ The prevalence of physical inactivity was $45.9 \%$ in men and $57.9 \%$ in women before cancer diagnosis; however, this rate remarkably decreased 5 years after cancer diagnosis, showing that only $1.1 \%$ of cancer survivors were physically inactive in both sexes. ${ }^{14)}$ Pre-exercise assessment and exercise capacity and functional test are recommended for some cancer survivors, especially patients who received chemohormonal treatments with cardiotoxic effects and those who developed chemotherapy-induced neuropathy. Thus, an individualized exercise plan is necessary considering survivors' cardiopulmonary function, comorbidities, and treatment modalities that they received. ${ }^{17)}$

While nutritional issues highly vary depending on the cancer type, stage, and treatment, generally, a diet high in vegetables, fruits, and whole grains is recommended for cancer survivors. During acute treatment, anorexia, nausea, vomiting, and changes in smell and taste are common; hence, the goal of nutritional support is to prevent malnutrition and maintain lean body weight. Individualized nutritional counseling can help survivors improve their dietary intake and prevent the occurrence of some toxicities associated with cancer treatment. ${ }^{18)}$ In the recovery stage, maintaining a healthy body weight is vital for survivorship care because obesity increases the risk of recurrence of breast and other cancers. ${ }^{19,20)}$ However, it remains unclear whether intentional weight reduction has a positive effect on the prognosis of cancer despite the limited number of evidence showing improved prognosis among survivors who lost weight with nutritional management. ${ }^{21)}$

The following is a description of surveillance for recurrence, late complications, comorbidities, and secondary cancer sites for stomach, colon, thyroid, breast, prostate, cervical, and lung cancer, with the highest 5-year survival and prevalence rates. Although various guidelines and research results have been reported, the guidelines published in Korea have been prioritized.

\section{Gastric Cancer}

As of 2016, the most common type of cancer affecting men and women was stomach cancer, and the relative 5-year survival rate (20122016) was $76.7 \%$ for men, $73.8 \%$ for women, and $75.8 \%$ for both sexes. ${ }^{1)}$ Endoscopy is recommended at least annually for recurrence surveillance in patients who have undergone endoscopic treatment for early gastric cancer. ${ }^{22)}$ For patients who underwent gastrectomy, there is no established guideline for the specific screening method and follow-up interval. Although follow-up is common in gastric cancer care, there is no evidence to support that it has any survival benefit. ${ }^{23)}$ However, experts recommend that patients with early gastric cancer should be examined for at least 5 years and after 5 years and should undergo endoscopy once a year. ${ }^{24,25)}$ Gastrectomy will be performed, except for some types of early gastric cancers, which are indications for endoscopic resection. Postoperative complications that may develop include dumping syndrome, gastric acid and bile reflux, delayed gastric emptying, and diarrhea. To prevent the development of dumping syndrome, patients should consume smaller meals more frequently and increase the intake of proteins instead of carbohydrates. To prevent gastric acid and bile reflux, overeating and lying down after meals should be avoided, and dinner should be served 4 hours before bedtime. After gastrectomy, metabolic disorders, such as anemia, bone disease, and weight loss, usually develop. In patients who underwent total gastrectomy, iron and vitamin B12 deficiencies often cause anemia. Therefore, it is necessary to prescribe iron supplementation and cyanocobalamin intramuscular injection. Moreover, according to the results of bone mass density (dual energy X-ray absorptiometry), calcium (calcium citrate preparation) and vitamin D supplements should be administered in cases of osteopenia, and performance of weightbearing exercises is recommended. ${ }^{25,26)}$ The relative incidence risk for secondary cancer in gastric cancer varies from study to study. According to the Osaka Cancer Registry Data study in Osaka, Japan, which has similar epidemiological characteristics to those of Korea, the standardized incidence ratio for secondary cancer after colon cancer was 1.86 for thyroid cancer, 1.68 for esophageal cancer, and 1.63 for breast cancer in women. ${ }^{27)}$ 


\section{Colorectal Cancer}

In 2016, colorectal cancer was the second most common cancer in Korea after stomach cancer. The 5-year relative survival rate (20122016) was $77.8 \%$ for men, $73.4 \%$ for women, and $76.0 \%$ for both sexes. ${ }^{1)}$ Approximately $80 \%$ of colorectal cancers recur within 2-2.5 years after diagnosis and have been categorized into different stages. However, there are no clear guidelines on the follow-up of patients with colon cancer in Korea. Although there are differences between various clinical guidelines, the United States National Comprehensive Cancer Network guidelines recommend that carcinoembryonic antigen test, chest/abdominal/pelvic computed tomography (CT), and colonoscopy should be performed at the pathologic stage (Table 1$){ }^{26-32)}$ The interval between colonoscopies is still unclear, but experts recommend that it should be conducted within 1 year after colon cancer surgery and every 3-5 years thereafter. ${ }^{33,34)}$ The goal of colorectal cancer treatment is radical resection. Long-term side effects of surgery include chronic diarrhea or incontinence, urination, and sexual dysfunction.
Additionally, long-term survivor studies, including those on colorectal cancer, reported that patients with cancer had a higher risk of developing cardiovascular diseases related to obesity, hypertension, diabetes, and physical inactivity than the general population. ${ }^{35)}$ Therefore, primary care physicians who are managing patients with colorectal cancer should provide active counseling to help these patients prevent the development of cardiovascular diseases. Moreover, patients with colorectal cancer are 1.68 times more likely to develop dementia than the general population, ${ }^{36)}$ while those who underwent chemotherapy and aged $>70$ years are more vulnerable to cognitive decline. ${ }^{37)}$ Secondary cancer incidence in colon cancer survivors varies from study to study, but it is known to increase the risk of thyroid, ovarian, uterine, kidney/urinary tract/bladder, and gastric cancer (Table 1). ${ }^{26-32)}$

\section{Lung Cancer}

Lung cancer was the fourth most common cancer in Korea in 2016, the second most common after gastric cancer in men, and the fifth

Table 1. Multidisciplinary care for cancer survivors in the primary care setting

\begin{tabular}{|c|c|c|c|c|}
\hline $\begin{array}{l}\text { First cancer } \\
\text { site }\end{array}$ & Surveillance for recurrence & Late complications & Comorbidities & $\begin{array}{c}\text { Secondary cancer site } \\
\text { (standardized incidence ratio) }^{27)}\end{array}$ \\
\hline Stomach & $\begin{array}{l}\text { Esophagogastroduodenoscopy once } \\
\text { a year }\end{array}$ & $\begin{array}{l}\text { Dumping syndrome, gastric acid } \\
\text { reflux, bile reflux, and gastroparesis }\end{array}$ & Anemia and osteoporosis & $\begin{array}{l}\text { Thyroid (1.86), esophagus (1.68), } \\
\text { and breast (1.63) }\end{array}$ \\
\hline Colon & $\begin{array}{l}\text { Every stage: colonoscopy at } 1 \text { year } \\
\text { postoperatively (with advanced } \\
\text { adenoma: repeat after } 1 \text { year; } \\
\text { without advanced adenoma: repeat } \\
\text { after } 3 \text { years and then every } \\
5 \text { years) } \\
\text { Stage II, III: carcinoembryonic antigen } \\
\text { test every } 3-6 \text { months for } 2 \text { years } \\
\rightarrow \text { every } 6 \text { months, for a total of } \\
5 \text { years } \\
\text { Chest/abdominal/pelvic CT every } \\
6 \text {-12 months, for a total of } \\
5 \text { years }\end{array}$ & $\begin{array}{l}\text { Chronic diarrhea or incontinence, } \\
\text { urinary difficulty, sexual } \\
\text { dysfunction, and infertility }\end{array}$ & $\begin{array}{l}\text { Cardiovascular disease and cognitive } \\
\text { dysfunction }\end{array}$ & $\begin{array}{c}\text { Thyroid (3.00), ovary (2.43), uterus } \\
\text { (1.64), kidney/urinary tract/bladder } \\
\text { (1.30), and stomach (1.28) }\end{array}$ \\
\hline Lung & $\begin{array}{l}\text { Chest CT every } 3-6 \text { months for the } \\
\text { first } 2 \text { years } \rightarrow \text { every } 6-12 \text { months } \\
\text { for } 3 \text { years } \rightarrow \text { annually after } \\
5 \text { years }^{28)}\end{array}$ & $\begin{array}{l}\text { Pain, respiratory difficulty, swallowing } \\
\text { difficulty, hoarseness, neurologic } \\
\text { symptoms, and pneumonitis }\end{array}$ & $\begin{array}{l}\text { Cardiocerebrovascular disease } \\
\text { (stroke, heart failure, ischemic } \\
\text { heart disease, and arrhythmia) } \\
\text { chronic obstructive pulmonary } \\
\text { disease, connective tissue disease, } \\
\text { and vascular disease }\end{array}$ & $\begin{array}{c}\text { Thyroid (4.29), larynx (2.51), mouth/ } \\
\text { pharynx (2.14), esophagus (2.04), } \\
\text { kidney/urinary tract/bladder (1.65), } \\
\text { stomach (1.39), colorectum (1.24) }\end{array}$ \\
\hline Breast & $\begin{array}{l}\text { Mammography every } 6-12 \text { months } \\
\text { for } 5 \text { years }^{29)}\end{array}$ & $\begin{array}{l}\text { Lymphedema, vasomotor symptom, } \\
\text { skin disease, musculoskeletal } \\
\text { disease, peripheral neuropathy, and } \\
\text { cardiac toxicity }\end{array}$ & $\begin{array}{l}\text { Diabetes mellitus, dyslipidemia, and } \\
\text { osteoporosis }\end{array}$ & $\begin{array}{l}\text { Thyroid (5.06), ovary (2.16), uterus } \\
\text { (2.07), esophagus (1.92), stomach } \\
\text { (1.40), and colorectum (1.20) }\end{array}$ \\
\hline Thyroid & $\begin{array}{l}\text { Measurement of thyroglobulin and } \\
\text { anti-thyroglobulin antibody every } \\
6-12 \text { months } \\
\text { Thyroid function test and thyroglobulin } \\
\text { and neck sonography every year }{ }^{30)}\end{array}$ & $\begin{array}{l}\text { Voice change, neck pain, and } \\
\text { hypocalcemia }\end{array}$ & $\begin{array}{l}\text { Atrial fibrillation, other cardiovascular } \\
\text { conditions, and low bone density in } \\
\text { postmenopausal women }\end{array}$ & Breast (1.21) and prostate (1.31) \\
\hline Cervix uteri & $\begin{array}{l}\text { Pap smear every } 3-6 \text { months for } \\
2 \text { years } \rightarrow \text { every } 6 \text { months for } \\
3 \text { years } \rightarrow \text { then annually }{ }^{31)}\end{array}$ & $\begin{array}{l}\text { Bladder dysfunction, bowel habit } \\
\text { change, sexual dysfunction, } \\
\text { lymphedema, and vaginal dryness }\end{array}$ & $\begin{array}{l}\text { Cardiovascular disease, hypertension, } \\
\text { liver disease, and gastrointestinal } \\
\text { disease }\end{array}$ & $\begin{array}{l}\text { Lung }(2.60), \text { colorectum }(1.56) \text {, and } \\
\text { breast }(1.40)\end{array}$ \\
\hline Prostate & $\begin{array}{l}\text { PSA test every } 3 \text { months for } 2 \text { years } \\
\text { postoperatively } \rightarrow \text { every } 6 \text { months } \\
\text { up to } 5 \text { years } \rightarrow \text { every year after } \\
5 \text { years }^{26)}\end{array}$ & $\begin{array}{l}\text { Urinary incontinence, sexual } \\
\text { dysfunction, flushing, } \\
\text { gynecomastia, osteoporosis, } \\
\text { cardiovascular disease, and } \\
\text { dementia }\end{array}$ & $\begin{array}{l}\text { Cardiovascular disease, dyslipidemia, } \\
\text { diabetes mellitus, and osteoporosis }\end{array}$ & $\begin{array}{l}\text { Urinary tract/bladder (2.21) and } \\
\text { colorectum (1.35) }\end{array}$ \\
\hline
\end{tabular}

$\mathrm{CT}$, computed tomography. 
most common in women. The 5-year relative survival rate was $23.2 \%$ for men, $37.9 \%$ for women, and $27.6 \%$ for both sexes, with an $11.1 \%$ increase compared with the previous 5-year survival rate. ${ }^{1)}$ Despite the relatively low 5 -year survival rate, primary physicians should pay attention to the health problems experienced by patients with lung cancer; their quality of life is seriously impaired due to pain and breathing difficulty, and various health problems can occur during the period of treatment, including increased cardiovascular risk. With regard to follow-up of patients after lung cancer treatment, chest CT is recommended every 3-6 months for the first 2 years, every 6-12 months for 3 years, and every year after 5 years. ${ }^{28)}$ Several studies have reported that low-dose chest CT is also useful in examining patients with cancer 5 years after treatment; however, domestic medical guidelines do not clearly indicate which CT is better, but low-dose chest CT may be used ${ }^{38)}$ Patients with lung cancer have severe pain after surgery, and approximately $30 \%$ of those who underwent thoracotomy have pain for up to 3-4 years due to neuropathy. ${ }^{39)}$ Additionally, the reduction in pulmonary function is evident up to 6 months after surgery, and rapid breathing due to breathing difficulties or breathing voice to vocal cord nerve damage and inhalation injury can lead to pneumonia and pulmonary thrombosis. ${ }^{26)}$ One of the most important comorbidities in lung cancer survivors is cardiocerebrovascular disease. ${ }^{40)}$ Moreover, patients with stage I-II lung cancer had a higher prevalence of chronic obstructive pulmonary disease (36.6\%), connective tissue disease (23.5\%), and peripheral vascular disease $(10.8 \%) .{ }^{41)}$ Secondary cancers that commonly develop in lung cancer survivors are thyroid, laryngeal, and pharyngeal; esophageal; urinary; stomach; and colon cancers (Table 1). ${ }^{26-32)}$

\section{Breast Cancer}

Breast cancer is the second most common cancer in Korean women after thyroid cancer, with a 5-year survival rate of 92.7\%. ${ }^{1)}$ According to the guidelines of the Korean Breast Cancer Society, follow-up mammography should be conducted for 5 years with a 6-month to 1-year interval. Regular examinations on the opposite breast are performed annually. If necessary, magnification mammography and breast ultrasonography can be performed. ${ }^{42)}$ Experts recommend annual mammography after 5 years. ${ }^{29)}$ Approximately $30 \%$ of patients with breast cancer may develop lymphedema, most cases of which are not treated and require ongoing management. Antihormonal therapy or chemotherapy can lead to sudden, premature menopause, which can cause vasomotor symptoms such as hot flashes and sweating. Furthermore, skin disease, musculoskeletal disease, and peripheral neuropathy of the arm treated after breast cancer surgery or after radiation therapy may develop. Moreover, radiation therapy, chemotherapy, and aromatase inhibitor therapy can increase the risk of cardiovascular disease in breast cancer survivors. ${ }^{26)}$ Not only does the risk of diabetes increase in breast cancer survivors, but diabetes also affects the prognosis of breast cancer, increasing the risk of breast cancer recurrence. Meanwhile, the use of metformin in patients with breast cancer with diabetes reduced the risk of breast cancer deaths, and the risk of breast can- cer in patients with diabetes who used metformin was lower than that in patients who used other medications. ${ }^{43)}$ The prevalence rate of hyperlipidemia in patients with breast cancer using aromatase inhibitor was $40 \%-60 \% .{ }^{44)}$ Moreover, $>80 \%$ of patients with breast cancer had bone loss due to treatment. ${ }^{45)}$ Secondary cancers that commonly develop among breast cancer survivors are thyroid, ovarian, uterine, esophageal, stomach, and colorectal cancers (Table 1). ${ }^{26-32)}$

\section{Thyroid Cancer}

Thyroid cancer is the third most common cancer in Korea, and the 5 -year relative survival rate is $100.2 \%$, which is greatly important for survival management. ${ }^{1)}$ Thyroid cancer survivors should undergo thyroglobulin and anti-thyroglobulin antibody test every 6-12 months and thyroid function test, thyroglobulin test, and neck ultrasonography every year. The high-risk group should maintain a thyroid-stimulating hormone (TSH) level of 0.1-0.5 $\mathrm{mU} / \mathrm{L}$, while the low-risk group should maintain a TSH level of $0.3-2 \mathrm{mU} / \mathrm{L}$ for 5-10 years postoperatively to treat thyroid hormone deficiency in the long-term follow-up phase. ${ }^{30)}$ Voice change is one of the most common symptoms in patients after thyroid cancer surgery and may be accompanied by neck and shoulder pain, exercise restriction, and sensory degradation due to surgical site adhesions. Hypocalcemia, causing numbness around the mouth and in the hands and feet, may also develop after thyroidectomy. ${ }^{26)}$ Thyroid hormone suppression therapy after thyroid cancer treatment may help patients maintain a state of subclinical hyperthyroidism. This condition increases the risk of atrial fibrillation and reduces bone mineral density in postmenopausal women. ${ }^{46,47)}$ Secondary cancers that developed in high-risk thyroid cancer survivors were breast cancer in women and prostate cancer in men (Table 1). ${ }^{26-32}$ )

\section{Prostate Cancer}

Prostate cancer is the most common type of cancer in Western men and the fourth most common type of cancer in male patients with cancer in Korea. It has a 5-year relative survival rate of 93.9\%. ${ }^{1)}$ Radical prostatectomy is the most commonly used treatment for local prostate cancer. Although domestic guidelines do not specifically indicate the frequency of measuring prostate-specific antigen (PSA) levels, PSA levels are usually measured every 3 months until the second year after surgery, every 6 months up to 5 years, and every year after 5 years. Postoperative complications may include urinary incontinence and sexual dysfunction. After androgen deprivation therapy, flushing, sexual dysfunction, gynecomastia, osteoporosis, cardiovascular disease, ${ }^{26)}$ and dementia ${ }^{48)}$ may develop. The common comorbidities in patients with prostate cancer include cardiovascular disease, dyslipidemia, diabetes mellitus, and osteoporosis. ${ }^{36)}$ Secondary cancers may commonly develop in the bladder and colorectum (Table 1). ${ }^{26-32)}$

\section{Cervical Cancer}

The incidence of cervical cancer has been on a steady decline since 1999, but this is considered to be due to the early diagnosis and treatment of cervical cancer rather than just an absolute decrease. It has a 
5-year relative survival rate of 79.8\%. ${ }^{1)}$ Patients with cervical cancer are recommended to undergo Pap smears every 3-4 months for the first 2 years, every 6 months for the next 3 years, and annually thereafter. Cervical cytology; laboratory tests; imaging tests such as pelvic/abdominal/chest CT, magnetic resonance imaging, and positron emission tomography; and tumor marker tests can be performed according to the clinical condition of the patient and judgment of the primary care provider. ${ }^{31)}$ Late complications of cervical cancer survivors include sexual dysfunction, voiding and abdominal symptoms, and lymphedema ${ }^{49)}$ Compared with the general population, cervical cancer survivors reported higher prevalence of comorbidities, such as cardiovascular disease, liver disease, hypertension, and gastrointestinal and musculoskeletal diseases. ${ }^{11)}$ Secondary cancers in cervical cancer survivors include lung, colon, and breast cancers. ${ }^{27)}$

\section{ROLE OF PRIMARY CARE IN THE MANAGEMENT OF CANCER SURVIVORS}

The spectrum of healthcare services provided in the primary care setting varies according to disease prevalence, unmet medical needs, care and educational capabilities of the primary practitioner, health policies, etc. As the number of cancer survivor increases, the role of primary care has become an important position in the management of cancer survivors; consequently, cancer survivorship care is recognized as an essential part of primary care. Conventional survivorship care provided by oncologists mainly consists of treatment of primary cancer and surveillance for recurrence of primary cancer as the diagnosis of cancer may shift patients' and oncologists' attention to cancer treatment; hence, non-cancer-related health issues, such as comorbidities, preventive services, and behavioral health consultation, are likely to be neglected in the time-limited oncology setting. ${ }^{50)}$ The Institute of Medicine (IOM) stated that this treatment-centered approaches are not suitable for cancer survivors dealing with various cancer-related and non-cancer health problems; thus, more comprehensive and coordinated care models are needed to address the gap between cancer treatment and cancer survivorship. ${ }^{51)}$

Primary care physicians are trained to manage various health problems and provide comprehensive and continuous care for patients with chronic medical conditions including cancer. Oncologists are responsible for providing primary cancer treatment, while primary care physicians are engaged in managing survivors' chronic medical conditions. This demonstrates that more patients received appropriate secondary primary cancer surveillance and optimal immunization. ${ }^{12)}$ Additionally, no substantial difference in quality of life, cancer recurrence rate, and cancer-related mortality was observed between the primary care physician follow-up group and oncologist follow-up group of early breast cancer survivors. ${ }^{52)}$ These results imply that shared care responsibility for cancer survivors between primary care physicians and oncologists could be a feasible way to deliver comprehensive care for patients with cancer.

Although it is important for primary care physicians to understand the cancer survivors' physical and psychological features to deliver tailored care for this population, there are inadequate educational opportunities and programs available for physicians, and a large proportion of the primary physicians feel uncomfortable caring for these patients because survivorship care was not incorporated in their formal educational course during the training. ${ }^{53)}$ Cancer survivors tend to consider that every cancer- and non-cancer-related disease can be detected via routine blood tests and CT. ${ }^{54)}$ Furthermore, they are likely not paying attention to the patients' chronic disease resulting in suboptimal compliance rate for hypertension treatment and diabetes care. ${ }^{55)}$ However, considering that chronic diseases are the major cause of death among long-term cancer survivors, with regard to disease prevention and health promotion, the role of primary care in cancer survivorship is expected to extend inevitably.

\section{SURVIVORSHIP CARE MODELS}

Several survivorship care models have been proposed in the United States and other Western countries, including exclusively primary care physician-led care model, oncologist-led specialized team care model, and risk-stratified shared care model that primary care physicians or practitioner nurses and the multidisciplinary team concurrently engage in to follow cancer survivors ${ }^{56)}$ and tackle the situation of "lost in transition" as stated by the IOM. ${ }^{51)}$ Moreover, the chronic care model, which emphasizes self-management of patients living with cancer, was suggested as another care model to facilitate interaction between informed patients who actively participate in the care process and experienced healthcare providers. ${ }^{57)}$ In the care continuum, this model might provide a perception of involving survivors in the care, higher care quality, and cost-effectiveness in several care settings. Of these models, the shared care model, which recommends the involvement of both oncologists and primary care physicians in survivorship care, has been mostly credited as a viable model across clinical settings. Moreover, this model can be applied in the Korean healthcare system. ${ }^{58)}$ Shared care model has positive effects on the quality of management for non-cancer-related health problems, and survivors preferred to be followed by both oncologists and primary care physicians. $^{59)}$

However, there are several challenges in implementing the riskstratified shared care model in the clinical practice of survivorship care. First, the specific role and responsibility of oncologists and primary care physicians in primary cancer follow-up, surveillance for secondary cancer, and provision of preventive services remain ambiguous, making it difficult to implement survivorship care in clinical practice. ${ }^{60)}$ Although it is necessary to clarify the care roles of these providers, different clinical settings and medical culture among hospitals and regions may disrupt the substantial progress in this issue. Suboptimal knowledge and confidence in survivorship care among primary care physicians and survivors' insufficient confidence with follow-up care delivered by primary physicians were noted as another challenge in the provision of survivorship care. ${ }^{61)}$ More educational 
opportunities for the primary physician regarding survivorship care and highly coordinated care between oncologists and primary care physician might help address the abovementioned challenges. A survivorship care plan, which summarizes the cancer status, brief treatment history, and future follow-up plan for primary cancer, was suggested to facilitate care communication between care providers; however, completing the care plan might be time consuming. With limited time and resources, several oncologists are reluctant to provide the treatment summary and future care plan as part of their routine care although they agree with the necessity of these materials. Finally, the lack of reimbursement for survivorship care is another barrier to the application of this model.

Considering the current oncology practices in Korea, the risk-stratified shared care model was slightly modified to provide an institutional-level survivorship care. ${ }^{50)}$ Because survivorship care is delivered in the same institution where survivors received primary cancer therapy, this model can address several issues regarding information sharing, accessibility of patients, and communication problem among different specialists using electronic medical records. Furthermore, being cared for at the same institution make cancer survivors feel comfortable and might be associated with less reluctance to transit from oncology care to primary care.

\section{NATIONAL POLICY FOR CANCER SURVIVOR AND FUTURE CHALLENGES}

The cancer policy branch of the National Cancer Control Institute developed an "integrative supportive care service delivery system for cancer survivors," which has a wider scope than the shared care model. The integrative supportive care team is composed of professionals for psycho-oncology, rehabilitation, pain management, nutritional support, social work services, etc. A coordinated care process was also established: A practitioner nurse assesses the care risks and needs of survivors, while dedicated physicians (i.e., family physicians or internists of the cancer center dedicated in survivorship care) evaluate the patients, provide appropriate care, or refer the patients to a specialist for consultation, if necessary. The needs of survivors, family members, and caregivers were assessed using a linear analogue thermometer scale.

Integrated supportive cancer survivorship centers were established by the Ministry of Health and Welfare as part of the National Cancer Control Plan in 2016. Eight cancer institutions were established in 2017 as part of the demonstration projects for shared care between regional cancer centers and public health centers; currently, 12 cancer centers are participating in the projects. Furthermore, a communitybased care model including primary care physicians in the community was developed to increase the cancer survivors' accessibility to survivorship care. To facilitate the successful implementation of integrated supportive cancer survivorship, efforts have been made to incorporate cancer survivorship as part of the Cancer Control Act.

However, several challenges were noted during the development of survivorship care based on the national public health perspectives. First, survivorship care should be established on a legal background, such as the Comprehensive Cancer Care Improvement Act in the United States. Second, the lack of reimbursement for each survivorship care item, such as treatment summary, future care plan, needs assessment, and transition visit, hinders advancement in survivorship care. Third, the limited number of care delivery institutions mostly located in the metropolitan area would make it difficult for cancer survivors living in rural areas to access survivorship services. Fourth, there are insufficient educational programs for community physicians who are unfamiliar with the standardized survivorship care for long-term cancer survivors. Finally, evidence-based practical guidelines based on vigorous research on Korean cancer survivors and tailored approaches for each individual are necessary.

\section{CONCLUSION}

The number of cancer survivors is rapidly increasing due to the early detection of cancer and improvement in treatment results. The health problems of cancer survivors after cancer diagnosis include cancer-related symptoms, health problems associated with cancer treatment, other symptoms that require relief, and new chronic diseases that are not related to cancer. As a result, cancer patients need comprehensive and ongoing healthcare, including follow-up care for recurrence of primary cancer, as well as secondary cancer screening, prevention of late complications and associated chronic diseases, smoking cessation, increased physical activity, and proper nutrition. For the optimal healthcare of patients with cancer, a shared care model in which oncologists and primary physicians complement each other and an integrative supportive care team with multidisciplinary specialists are helpful. In the future, care systems for efficient and appropriate management of cancer survivors, a legal background for survivorship care, and evidence-based practical guidelines should be established.

\section{CONFLICT OF INTEREST}

No potential conflict of interest relevant to this article was reported.

\section{ORCID}

Jihun Kang: https://orcid.org/0000-0002-2263-9054

Eun Ju Park: https://orcid.org/0000-0003-2415-8243

Jungkwon Lee: https://orcid.org/0000-0001-5503-9605

\section{REFERENCES}

1. Jung KW, Won YJ, Kong HJ, Lee ES. Cancer statistics in Korea: incidence, mortality, survival, and prevalence in 2016. Cancer Res Treat 2019;51:417-30.

2. Mullan F. Seasons of survival: reflections of a physician with cancer. $\mathrm{N}$ Engl J Med 1985;313:270-3. 
3. Goo AJ, Song YM, Shin J, Ko H. Factors associated with depression assessed by the patient health questionnaire- 2 in long-term cancer survivors. Korean J Fam Med 2016;37:228-34.

4. Park W, Lee JK, Kim CR, Shin JY. Factors associated with fatigue in Korean gastric cancer survivors. Korean J Fam Med 2015;36:328-34.

5. Ligibel JA, Denlinger CS. New NCCN guidelines for survivorship care. J Natl Compr Canc Netw 2013;11:640-4.

6. Lee KS, Chang HS, Lee SM, Park EC. Economic burden of cancer in Korea during 2000-2010. Cancer Res Treat 2015;47:387-98.

7. Shin DW, Cho B, Kim SY, Jung JH, Park JH. Management of cancer survivors in clinical and public health perspectives: current status and future challenges in Korea. J Korean Med Sci 2013;28:651-7.

8. Kim J, Hahm MI, Park EC, Park JH, Park JH, Kim SE, et al. Economic burden of cancer in South Korea for the year 2005. J Prev Med Public Health 2009;42:190-8.

9. Cho J, Guallar E, Hsu YJ, Shin DW, Lee WC. A comparison of cancer screening practices in cancer survivors and in the general population: the Korean national health and nutrition examination survey (KNHANES) 2001-2007. Cancer Causes Control 2010;21:2203-12.

10. Patnaik JL, Byers T, Diguiseppi C, Denberg TD, Dabelea D. The influence of comorbidities on overall survival among older women diagnosed with breast cancer. J Natl Cancer Inst 2011;103:1101-11.

11. Shin DW, Nam JH, Kwon YC, Park SY, Bae DS, Park CT, et al. Comorbidity in disease-free survivors of cervical cancer compared with the general female population. Oncology 2008;74:207-15.

12. Earle CC, Neville BA. Under use of necessary care among cancer survivors. Cancer 2004;101:1712-9.

13. Parsons A, Daley A, Begh R, Aveyard P. Influence of smoking cessation after diagnosis of early stage lung cancer on prognosis: systematic review of observational studies with meta-analysis. BMJ 2010;340:b5569.

14. Park YM IH, Shin DW, Yun JM, Seo BS. Analysis of health behaviors and medical use of cancer survivors. Goyang: National Health Insurance Service Ilsan Hospital; 2015.

15. Park JJ, Park HA. Prevalence of cigarette smoking among adult cancer survivors in Korea. Yonsei Med J 2015;56:556-62.

16. Meyerhardt JA, Giovannucci EL, Holmes MD, Chan AT, Chan JA, Colditz GA, et al. Physical activity and survival after colorectal cancer diagnosis. J Clin Oncol 2006;24:3527-34.

17. Schmitz KH, Courneya KS, Matthews C, Demark-Wahnefried W, Galvao DA, Pinto BM, et al. American College of Sports Medicine roundtable on exercise guidelines for cancer survivors. Med Sci Sports Exerc 2010;42:1409-26.

18. Schattner M, Shike M. Nutrition support of the patient with cancer. In: Shils ME, Shike M, Ross AC, Caballero B, Cousins RJ, editors. Modern nutrition in health and disease. 10th ed. Philadelphia (PA): Lippincott Williams \& Wilkins; 2006. p. 1290-313.

19. Carmichael AR. Obesity and prognosis of breast cancer. Obes Rev 2006;7:333-40.

20. Siegel EM, Ulrich CM, Poole EM, Holmes RS, Jacobsen PB, Shibata D. The effects of obesity and obesity-related conditions on colorectal cancer prognosis. Cancer Control 2010;17:52-7.

21. Capuano G, Grosso A, Gentile PC, Battista M, Bianciardi F, Di Palma A, et al. Influence of weight loss on outcomes in patients with head and neck cancer undergoing concomitant chemoradiotherapy. Head Neck 2008;30:503-8.
22. Lee JH, Kim JG, Jung HK, Kim JH, Jeong WK, Jeon TJ, et al. Synopsis on clinical practice guideline of gastric cancer in Korea: an evidencebased approach. Korean J Gastroenterol 2014;63:66-81.

23. Cardoso R, Coburn NG, Seevaratnam R, Mahar A, Helyer L, Law C, et al. A systematic review of patient surveillance after curative gastrectomy for gastric cancer: a brief review. Gastric Cancer 2012;15:S164-7.

24. Sano T, Sasako M, Kinoshita T, Maruyama K. Recurrence of early gastric cancer: follow-up of 1475 patients and review of the Japanese literature. Cancer 1993;72:3174-8.

25. Shin DW, Yoo SH, Sunwoo S, Yoo MW. Management of long-term gastric cancer survivors in Korea. J Korean Med Assoc 2016;59:256-65.

26. Seo HK, Park JH. Evidence based cancer survival management. Goyang: National Cancer Center; 2013.

27. Tabuchi T, Ito Y, Ioka A, Miyashiro I, Tsukuma H. Incidence of metachronous second primary cancers in Osaka, Japan: update of analyses using population-based cancer registry data. Cancer Sci 2012;103: 1111-20.

28. Korean Association for Lung Cancer. Lung cancer clinical practice guideline. Seoul: Korean Association for Lung Cancer; 2011.

29. Chae BJ, Song BJ, Jung SS. Postoperative treatment strategy and follow up management for breast cancer patients in Korea. Korean J Clin Oncol 2009;5:21-6.

30. Yi KH, Lee EK, Kang HC, Koh Y, Kim SW, Kim IJ, et al. 2016 Revised Korean thyroid association management guidelines for patients with thyroid nodules and thyroid cancer. Int J Thyroidol 2016;9:59-126.

31. Korean Society of Gynecologic Oncology. Practice guideline for gynecologic cancer. 3rd ed. Seoul: Korean Society of Gynecologic Oncology; 2016.

32. National Comprehensive Cancer Network. NCCN clinical practice guidelines in oncology: colon cancer. 2nd ed. Plymouth Meeting (PA): National Comprehensive Cancer Network; 2019.

33. Scholefield JH, Steele RJ; British Society For Gastroenterology; Association of Coloproctology for Great Britain and Ireland. Guidelines for follow up after resection of colorectal cancer. Gut 2002;51:V3-5.

34. Hwang C. Follow-up colonoscopy after colorectal cancer surgery. Korean J Gastrointest Endosc 2003;27:297-9.

35. Weaver KE, Foraker RE, Alfano CM, Rowland JH, Arora NK, Bellizzi $\mathrm{KM}$, et al. Cardiovascular risk factors among long-term survivors of breast, prostate, colorectal, and gynecologic cancers: a gap in survivorship care? J Cancer Surviv 2013;7:253-61.

36. Khan NF, Mant D, Carpenter L, Forman D, Rose PW. Long-term health outcomes in a British cohort of breast, colorectal and prostate cancer survivors: a database study. Br J Cancer 2011;105:S29-37.

37. Jansen L, Hoffmeister M, Chang-Claude J, Koch M, Brenner H, Arndt V. Age-specific administration of chemotherapy and long-term quality of life in stage II and III colorectal cancer patients: a population-based prospective cohort. Oncologist 2011;16:1741-51.

38. Lou F, Huang J, Sima CS, Dycoco J, Rusch V, Bach PB. Patterns of recurrence and second primary lung cancer in early-stage lung cancer survivors followed with routine computed tomography surveillance. J Thorac Cardiovasc Surg 2013;145:75-81.

39. Yun YH, Kim YA, Min YH, Chang YJ, Lee J, Kim MS, et al. Health-related quality of life in disease-free survivors of surgically treated lung cancer compared with the general population. Ann Surg 2012;255: 1000-7. 
40. Kravchenko J, Berry M, Arbeev K, Lyerly HK, Yashin A, Akushevich I. Cardiovascular comorbidities and survival of lung cancer patients: Medicare data based analysis. Lung Cancer 2015;88:85-93.

41. Tammemagi CM, Neslund-Dudas C, Simoff M, Kvale P. Impact of comorbidity on lung cancer survival. Int J Cancer 2003;103:792-802.

42. Korean Breast Cancer Society. The 6th Korean clinical practice recommendations of breast cancer. 6th ed. Seoul: Korean Breast Cancer Society; 2015.

43. Calip GS, Yu O, Hoskins KF, Boudreau DM. Associations between diabetes medication use and risk of second breast cancer events and mortality. Cancer Causes Control 2015;26:1065-77.

44. Wasan KM, Goss PE, Pritchard PH, Shepherd L, Palmer MJ, Liu S, et al. The influence of letrozole on serum lipid concentrations in postmenopausal women with primary breast cancer who have completed 5 years of adjuvant tamoxifen (NCIC CTG MA.17L). Ann Oncol 2005;16: 707-15.

45. Chen Z, Maricic M, Pettinger M, Ritenbaugh C, Lopez AM, Barad DH, et al. Osteoporosis and rate of bone loss among postmenopausal survivors of breast cancer. Cancer 2005;104:1520-30.

46. Sawin CT. Subclinical hyperthyroidism and atrial fibrillation. Thyroid 2002;12:501-3.

47. Donangelo I, Braunstein GD. Update on subclinical hyperthyroidism. Am Fam Physician 2011;83:933-8.

48. Nead KT, Gaskin G, Chester C, Swisher-McClure S, Leeper NJ, Shah $\mathrm{NH}$. Association between androgen deprivation therapy and risk of dementia. JAMA Oncol 2017;3:49-55.

49. Wenzel L, DeAlba I, Habbal R, Kluhsman BC, Fairclough D, Krebs LU, et al. Quality of life in long-term cervical cancer survivors. Gynecol Oncol 2005;97:310-7.

50. Shin DW, Kim Y, Baek YJ, Mo HN, Choi JY, Cho J. Oncologists experience with second primary cancer screening: current practices and barriers and potential solutions. Asian Pac J Cancer Prev 2012;13:6716.

51. Hewitt ME, Greenfield S, Stovall E. From cancer patient to cancer sur- vivor: lost in transition. Washington (DC): National Academies Press; 2006.

52. Grunfeld E, Levine MN, Julian JA, Coyle D, Szechtman B, Mirsky D, et al. Randomized trial of long-term follow-up for early-stage breast cancer: a comparison of family physician versus specialist care. J Clin Oncol 2006;24:848-55.

53. Susanibar S, Thrush CR, Khatri N, Hutchins LF. Cancer survivorship training: a pilot study examining the educational gap in primary care medicine residency programs. J Cancer Surviv 2014;8:565-70.

54. Shin DW, Kim YW, Oh JH, Kim SW, Chung KW, Lee WY, Let al. Knowledge, attitudes, risk perception, and cancer screening behaviors among cancer survivors. Cancer 2011;117:3850-9.

55. Shin DW, Park JH, Park JH, Park EC, Kim SY, Kim SG, et al. Antihypertensive medication adherence in cancer survivors and its affecting factors: results of a Korean population-based study. Support Care Cancer 2010;19:211-20.

56. Halpern MT, Viswanathan M, Evans TS, Birken SA, Basch E, Mayer DK. Models of cancer survivorship care: overview and summary of current evidence. J Oncol Pract 2015;11:e19-27.

57. Bodenheimer T, Wagner EH, Grumbach K. Improving primary care for patients with chronic illness: the chronic care model, part 2. JAMA 2002;288:1909-14.

58. Oeffinger KC, McCabe MS. Models for delivering survivorship care. J Clin Oncol 2006;24:5117-24.

59. Emery JD, Jefford M, King M, Hayne D, Martin A, Doorey J, et al. ProCare trial: a phase II randomized controlled trial of shared care for follow-up of men with prostate cancer. BJU Int 2017;119:381-9.

60. Cheung WY, Neville BA, Cameron DB, Cook EF, Earle CC. Comparisons of patient and physician expectations for cancer survivorship care. J Clin Oncol 2009;27:2489-95.

61. Mao JJ, Bowman MA, Stricker CT, DeMichele A, Jacobs L, Chan D, et al. Delivery of survivorship care by primary care physicians: the perspective of breast cancer patients. J Clin Oncol 2009;27:933-8. 